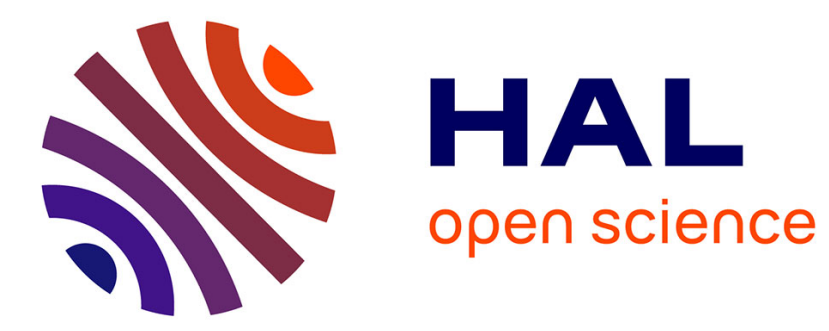

\title{
The ecological and evolutionary trajectory of oak powdery mildew in Europe
}

Marie-Laure Desprez-Loustau, Frédéric Marie Hamelin, Benoit Marçais

\section{To cite this version:}

Marie-Laure Desprez-Loustau, Frédéric Marie Hamelin, Benoit Marçais. The ecological and evolutionary trajectory of oak powdery mildew in Europe. Wildlife Disease Ecology, 1, Cambridge University Press, pp.429-457, 2019, 10.1017/9781316479964.015 . hal-02434813

\section{HAL Id: hal-02434813 https://hal.science/hal-02434813}

Submitted on 10 Jan 2020

HAL is a multi-disciplinary open access archive for the deposit and dissemination of scientific research documents, whether they are published or not. The documents may come from teaching and research institutions in France or abroad, or from public or private research centers.
L'archive ouverte pluridisciplinaire HAL, est destinée au dépôt et à la diffusion de documents scientifiques de niveau recherche, publiés ou non, émanant des établissements d'enseignement et de recherche français ou étrangers, des laboratoires publics ou privés. 
In: Wilson, K., Fenton, A., \& Tompkins, D. (Eds.). (2019). Wildlife Disease Ecology: Linking Theory to Data and Application (Ecological Reviews). Cambridge: Cambridge University Press.

doi:10.1017/9781316479964

pp 429-457, Doi: $\underline{10.1017 / 9781316479964.015}$

\title{
15. The ecological and evolutionary trajectory of oak powdery mildew in Europe
}

\author{
Marie-Laure Desprez-Loustau¹, Frédéric M. Hamelin² \& Benoit Marçais ${ }^{3}$
}

\begin{abstract}
'UMR 1202 BIOGECO, INRA, Univ. Bordeaux, 33610 Cestas, France, marie-laure.desprez-loustau@inra.fr
${ }^{2}$ IGEPP, Agrocampus Ouest, INRA, Université de Rennes 1, Université Bretagne-Loire, 35000 Rennes,

France, Frederic.hamelin@agrocampus-ouest.fr

3UMR 1136 IAM, INRA, Université de Lorraine, 54280, Champenoux, France, benoit.marcais@inra.fr
\end{abstract}

\section{Lay summary.}

Powdery mildew is a relatively new yet already common foliar disease of European oak trees, caused by a complex of fungal species that coevolved with Asian oaks and were introduced to Europe last century. To explore its eco-evolutionary dynamics, we developed a semi-discrete model combining a SIR model in the epidemic phase and a discrete-time model between years. This model, based on a within year - between year transmission trade-off, adequately described two main features of the disease: seasonality and the occurrence of a pathogen complex. We discuss refinement of this model and other modelling approaches for the evolution of virulence and resistance in a context of changing environment.

\section{Abstract.}

Oak powdery mildew in Europe is an example of disease in a wild perennial plant which has displayed dramatic changes over the course of a century; from typical invasion dynamics after pathogen introduction into a new area, characterized by severe damage, to a new equilibrium with moderate damage. Several non-mutually exclusive hypotheses could account for this, including pathogen evolution towards lower virulence, a reciprocal increase in oak population resistance, and both environmental biotic (phyllosphere microbes) and abiotic (climate) factors. We show that understanding the pathosystem requires the accounting of both seasonality (i.e. succession of epidemic and interepidemic phases linked to availability of susceptible leaves) and the occurrence of a pathogen complex with several cryptic fungal species differing in their life history traits. Observational data suggests that the severity of annual epidemics is linked to inter-annual pathogen transmission, including winter survival and the infection success of the primary inoculum in spring. Climate-driven phenological synchrony between host and pathogen in spring thus appears to be a critical factor. Several cryptic Erysiphe species are associated with the disease and co-occur at multiple spatial scales from individual leaves to continent. A semi-discrete model combining a SIR model in the epidemic phase and a discrete-time model between years, based on a within season (intra-epidemic) - between season (interepidemic) transmission trade-off, adequately describes seasonality and the coexistence of pathogen species. We discuss the refinement of this model, through the introduction of age classes in the host population in particular, and other modelling approaches for the evolution of pathogen virulence and host resistance in a context of changing environment. 

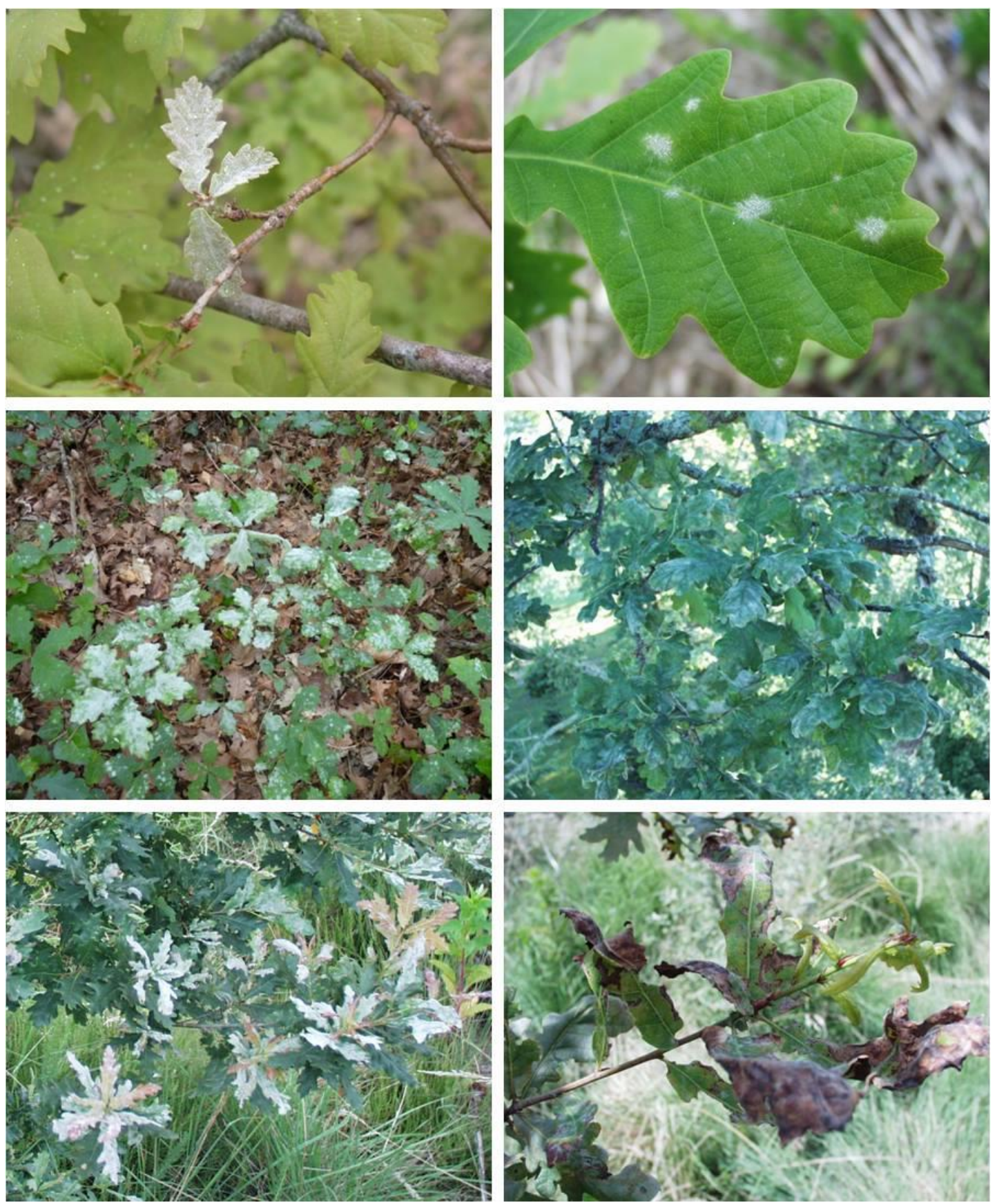

Figure 15.1 Oak powdery mildew symptoms. Clockwise from upper left corner: (1) first symptoms visible in spring, the flag shoots, corresponding to heavily infected shoots (=covered in mycelium and spores giving a white, cottony appearance) developing from buds infected in the previous season; (2) primary infections (white spots) corresponding to ascospore-derived colonies; (3) severe infection on oak seedlings; (4) infection on leaves of the first flush in a mature oak tree; (5) infection of the second flush is generally much more severe than that of the first flush; (6) severe infection leads to necrosis, distortion, early senescence of leaves and, finally, defoliation.

\subsection{Introduction.}

All plants interact with a diversity of pathogens, increasingly recognized as playing major roles in population and community ecology and evolutionary dynamics (e.g. Mordecai, 2011; Bever et al., 2015). Although by definition pathogens inflict fitness costs to the individuals they infect, their effects in natural plant communities may be subtle, often passing unnoticed. Indeed, disease impact is rarely catastrophic over large spatial scales in co-evolved systems. Disease prevalence may be high at the meta-population level, but epidemics in wild plant - pathogen systems ('pathosystems', sensu Robinson, 1976) are often limited in time and space and have a low to moderate impact (Burdon et al., 2013; Jousimo et al., 2014). By contrast, plant diseases may have catastrophic effects in agricultural ecosystems or when new (non-native) pathogens are introduced into plant communities (Pautasso et al., 2005). Agricultural ecosystems are characterized by high environmental and genetic uniformity, 
favouring pathogen transmission and leading to the emergence of highly virulent host-specialized plant pathogens (Stukenbrock \& McDonald, 2008). Conversely, wild plant communities are much more diverse but can be severely affected by introduced non-co-evolved pathogens (Pautasso et al., 2005; Desprez-Loustau et al., 2007).

Despite the contrasting features of different plant-pathogen associations (i.e. wild versus cultivated ecosystems, co-evolved versus non-coevolved interactions), Burdon et al. (2013) suggested they could be placed on the same continuum. Trajectories along this continuum are driven by ecological and genetic changes which contribute to the dynamic stability/instability of host-pathogen associations at different times. Oak powdery mildew in Europe illustrates this concept well. This foliar disease (Figure 15.1 ) is now one of the most common in European forests. It generally has moderate impact with highly variable prevalence over space and time, as typical of native plant-pathogen associations (Marçais \& Desprez-Loustau, 2014). However very severe damage, including high local mortality rates, was reported when the disease suddenly appeared and spread throughout Europe at the start of the twentieth century (Mougou et al., 2008; Figure 15.2). This raised fears that European oaks might disappear, just as current pathogen invasions are considered a threat to indigenous forest species (e.g. ash dieback caused by Hymenoscyphus fraxineus; Pautasso et al., 2013). The invasion of Europe by oak powdery mildew thus provides a case study for investigating the mechanisms underlying the epidemiological and evolutionary trajectory from a typical invasion pattern, towards the establishment of a new pathosystem in which the pathogen is integrated into its new environment.

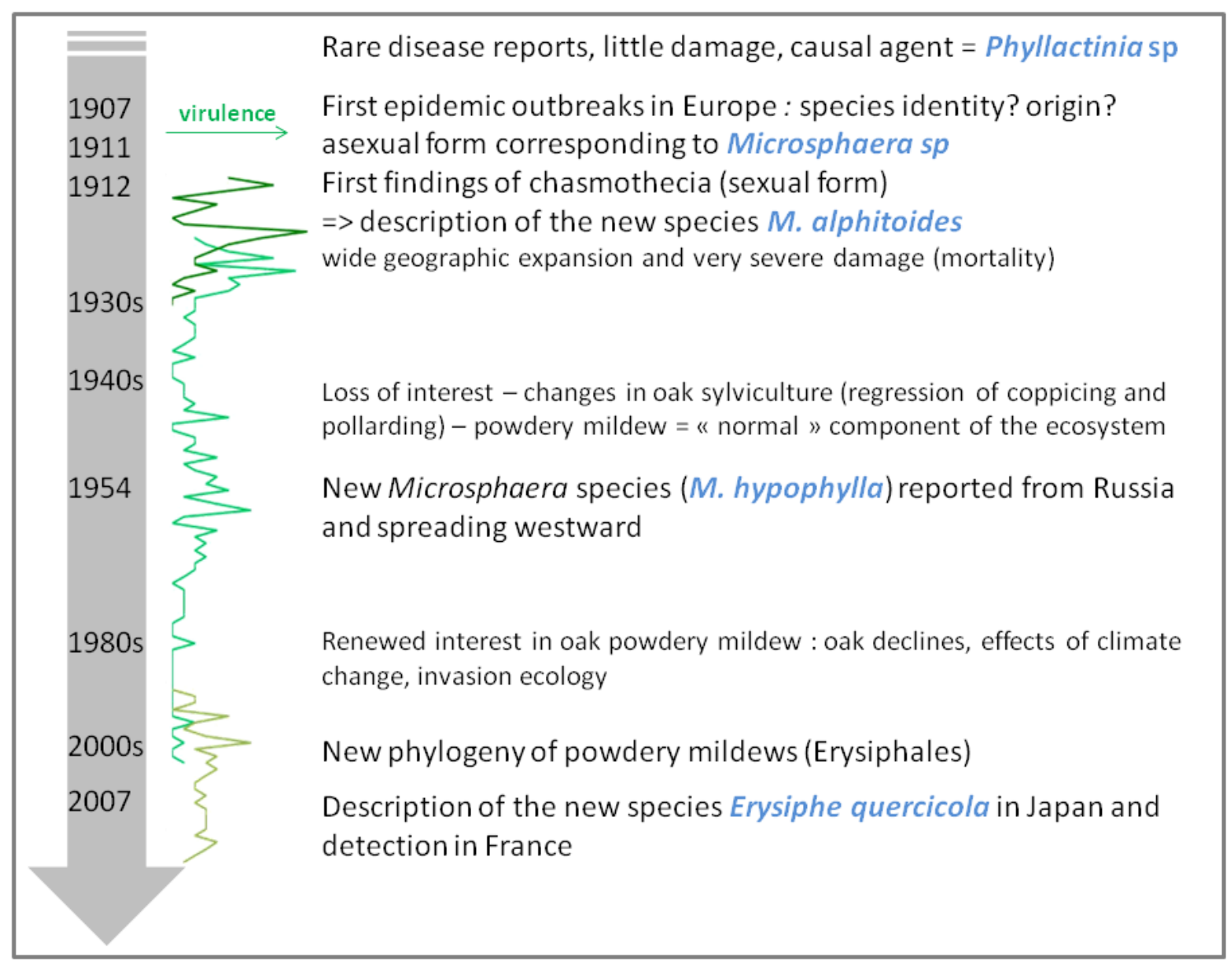

Figure 15.2 Short history of oak powdery mildew disease in Europe, showing the successive invasions (and descriptions) of several fungal pathogen species. Temporal trends of virulence, defined as the damage caused by disease in oak stands, were reconstructed from an analysis of the literature (represented as green lines on the left). Three proxies for virulence (represented with different shades) were extracted from: (1) 1912-1931, Annales des Epiphyties (France) - number of expressions related to oak powdery mildew damage in "Annual phytopathological reports"; (2) Review of Applied Mycology (1922 à 1970) and WoS (1970-2000) - number of publications dedicated to oak powdery mildew; (3) 1989-2015, French National Health Service (DSF) - index of disease severity. 
Several non-mutually exclusive hypotheses may explain the observed trajectory of the oak powdery mildew pathosystem. Evolution of the pathogen towards lower virulence might be expected (Sacristan \& Garcia-Arenal, 2008). Models predict evolution of virulence to intermediate levels when very high virulence is associated with lower pathogen fitness due to host death, i.e. when the positive relationship between transmission and virulence saturates and becomes a trade-off (Bull, 1994; Lenski \& May, 1994). Furthermore, theory predicts that, early in emergence before an evolutionary equilibrium is reached, epidemic conditions (particularly the availability of large populations of susceptible hosts) can impose a transient selection pressure leading to high virulence. This pressure subsequently decreases as the epidemic depletes the pool of susceptible hosts (Bull \& Ebert, 2008; Berngruber et al., 2013). There are very few examples of plant pathosystems supporting these theoretical predictions (Jarosz \& Davelos, 1995; but see Escriu et al., 2003). However, what is known of the history of oak powdery mildew in Europe (Mougou et al., 2008) suggests that this system may follow this pattern (Figure 15.2). Unfortunately, experimental support through comparative inoculation studies is not possible in the absence of a historical strain collection.

Jarosz \& Davelos (1995) suggested that important characteristics of many plant pathosystems challenge the pivotal assumptions of simple adaptive models of virulence. First, although classical epidemiological models developed for animal and human populations assume that host availability ultimately limits pathogen populations, the suitability of environmental conditions may also be a critical factor for plant pathogens, as illustrated by the disease triangle (i.e. plant, pathogen and environment) widely used by plant pathologists (Francl, 2001). In particular, for a biotrophic foliar pathogen of a broadleaf tree like oak powdery mildew, climate-driven seasonality is expected to have very strong direct and indirect effects (Penczykowski et al., 2015; Tack \& Laine, 2014). Second, multiple infections of one or several pathogens on the same host is the rule rather than the exception in plants, even if a single disease is considered. The use of advanced molecular techniques has revealed a huge previously undescribed fungal diversity (e.g. Tedersoo et al., 2014), leading to the suggestion that many plant pathogens represent several closely related sibling or cryptic species (Crous \& Groenewald, 2005; Feau et al., 2011). Many plant diseases are therefore caused by a complex of different pathogens, as was recently shown for oak powdery mildew (Takamatsu et al., 2007).

In this chapter, we provide an overview of the available empirical data for the oak powdery mildew pathosystem, showing how these data support and call into question evolutionary epidemiology theory, in the context of a novel interaction following the introduction of the pathogen. We first explore the potential effects of seasonality and the occurrence of a pathogen complex on theoretical predictions of the evolution of virulence, and more generally the eco-evolutionary dynamics of the pathosystem. We then consider the evolution of oak resistance, including the evolutionary potential of oak populations under powdery mildew pressure and the possible role of the biotic environment of the pathogen in the phyllosphere.

\subsection{Climate-driven seasonality: inter-annual disease transmission.}

Evolution of virulence has classically been explored through SIR epidemic models in which the host population is continuously present (Anderson \& May, 1982; Alizon et al., 2009). Models of epidemic disease in animals generally take seasonality into account through fluctuations in the disease transmission rate (Keeling \& Rohani, 2008). In contrast, for many plant diseases (e.g. of annual plants, or foliar diseases of deciduous trees), the host is present during only a fraction of the year (referred to hereafter as the 'season'). At the end of the season, infected material is removed (e.g. dead plants or leaves) and the parasite switches to survival forms (e.g. overwintering in leaf debris in the soil litter, or in dormant buds of perennial hosts). At the beginning of the next growth period, the survival forms of the parasite generate primary infections in the host population, initiating a new epidemic cycle. Secondary host-to-host infections then take over from primary infections.

Plant disease dynamics over several seasons have therefore been explored through models combining discrete-time events (including periodic demographic crashes in the host and pathogen populations) with continuous-time epidemiological dynamics over the season (Madden et al., 2007; Van den Berg et al., 2011). Models combining continuous- and discrete-time dynamics are widely used in biomathematics and are sometimes termed semi-discrete models (Mailleret \& Lemesle, 2009). Such a model accounting for effects of seasonality on the evolution of pathogen virulence is presented in Box 
15.1. In this context, the duration of host absence becomes a key parameter. Exploring the effects of seasonality, Van den Berg et al. (2011) suggested, in addition to the virulence-transmission trade-off, a second trade-off may occur between pathogen transmission during the season and pathogen survival outside it. The virulence outcome depends on which trade-off is most relevant. If the virulencetransmission trade-off prevails, pathogen transmission and virulence are predicted to decrease with decreasing off-season duration. In contrast, if the transmission-survival trade-off prevails, pathogen transmission (and possibly virulence) is predicted to increase with decreasing off-season duration. Relevant to oak powdery mildew, records of winter temperature in Europe show a long-term warming trend. Tree phenology has already changed significantly during the last century with both earlier budburst in spring and later leaf fall in autumn (Sparks \& Carey, 1995; Menzel 2000). For oak, this earlier budburst may account for a $10 \%$ increase in the duration of leaf presence since the 1950s (Sparks et al., 1997).

It remains difficult to attribute changes in oak powdery mildew virulence to past effects of climate, as it is unclear which of the two trade-offs (virulence-transmission or transmission-survival) prevails in this system. Decreasing virulence during the twentieth century implies that the virulence-transmission trade-off prevails. However, aerially dispersed plant pathogens are potentially subject to both tradeoffs (Van den Berg et al., 2011). In oak powdery mildew, premature leaf shedding observed in response to high levels of infection (Hajji et al., 2009) may underlie both trade-offs by immediately decreasing the pool of spores available for secondary infections (i.e. within season transmission) and preventing the fungus from forming its resting structures (for overwintering) in autumn on senescent leaves (see below).
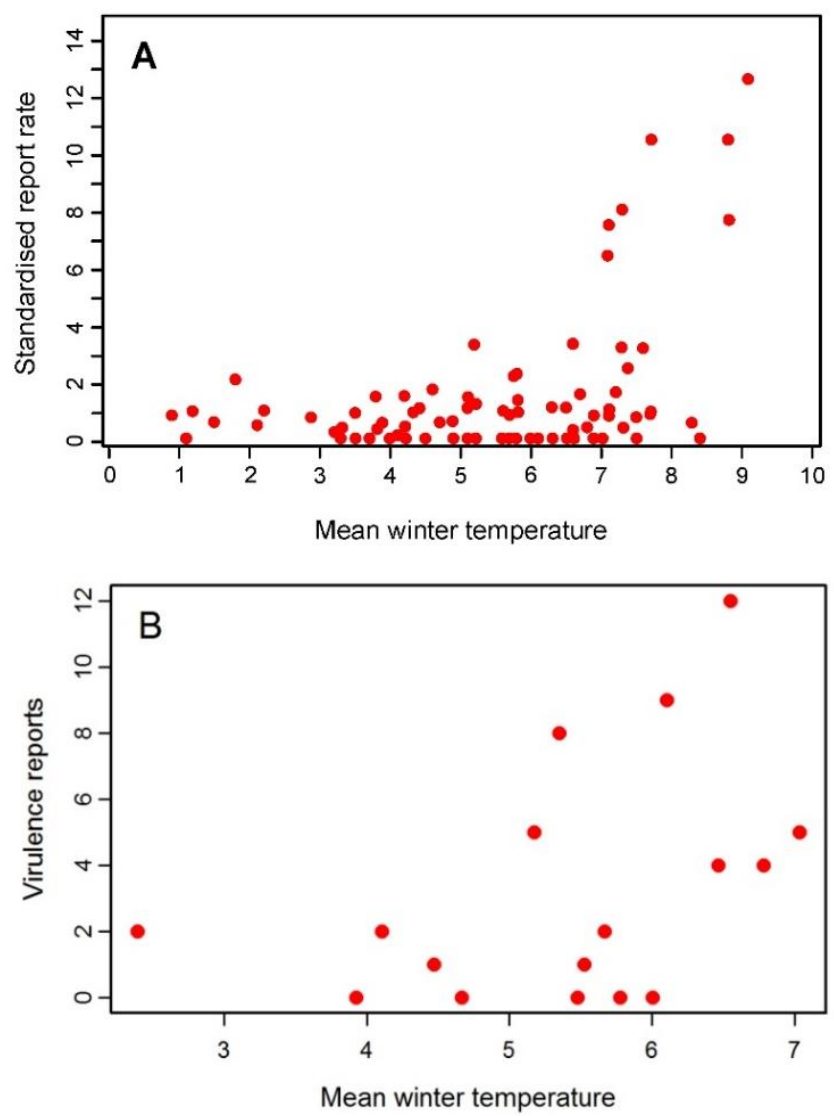

Figure 15.3 Winter temperature and oak powdery mildew disease in France. Disease data from two periods: (A) 1912-1931 (Annual phytopathological reports of "Annales des Epiphyties") and (B) 1989-2006 (Disease reports in the DSF database see Marçais \& Desprez-Loustau, 2014) - Meteorological data from Meteo France.

Environmental conditions during the off-season are very important for oak powdery mildew epidemiology, as highlighted for another powdery mildew disease on a wild herbaceous plant (Penczykowski et al., 2015; Tack et al., 2014) and other tree diseases (e.g. Aguayo et al., 2014). The analysis of climatic variables related to between-year variation in oak powdery mildew severity showed unexpectedly that off-season variables (such as winter temperature in particular), rather than climatic 
variables during the season, had significant effects with severe epidemics occurring only after mild winters (Marçais \& Desprez-Loustau, 2014). Interestingly, the role of warm winters in the severity of epidemics in the early twentieth century was emphasized by some authors (Vuillemin, 1910a). Colder winters in the following decades (http://www.meteofrance.fr/documents/10192/35608/25066-43.gif/) may partly account for the reported decrease in disease severity after the 1920s (Figure 15.2).

Off-season environmental conditions may affect between-season disease transmission through different mechanisms. Cold winters may decrease pathogen survival. Powdery mildews overwinter in two forms (Figure 15.4), mycelium and spores persisting on leaf primordia within dormant buds protected by bud scales, and specialised resting structures called chasmothecia (the sexual fruiting bodies of the fungus, with thick melanised walls) which form on infected leaves in the autumn (Glawe, 2008). Chasmothecia may remain on dead leaves in the litter or may detach from the leaves and come to rest in bark crevices and leaf scars on the trunk, which may provide the best sites for overwintering (Pearson \& Gadoury, 1987). For overwintering in dormant buds, primary inoculum consists of the highly infected shoots emerging from infected buds at budburst, called "flag shoots". For overwintering as chasmothecia, the primary inoculum consists of ascospores, generated in these fruiting bodies once dormancy has been released. Several cycles of secondary infections occur over the season in both cases, mediated by conidia (asexually produced spores; Figure. 15.4).

Winter climatic conditions may be a major factor determining which overwintering mode prevails, as observed for other plant parasites (Halkett et al., 2004). Most tropical powdery mildew species lack chasmothecia (Piepenbring et al., 2011). Conversely, for hop and apple powdery mildews, very low temperatures have been shown to have a deleterious effect on fungal survival in buds (Liyanage \& Royle, 1976; Spotts \& Chen, 1984), and there is also evidence of better oak powdery mildew survival in buds during mild winters (Marçais, et al. 2017). Despite this sensitivity, pathogen hibernation in buds has the advantage of providing a "green bridge" between two growing seasons in temperate climates; the pathogen experiences no discontinuity in host availability and can resume its development in perfect synchrony with that of the host as soon as weather conditions are favorable for leaf development.

Between-season transmission may also be affected by off-season temperature through effects on synchrony between bud burst and ascospore release from chasmothecia. Oak leaves display ontogenic resistance, i.e. they are susceptible to powdery mildew only a short period after their emergence (Edwards \& Ayres, 1982). The temporal coincidence of ascospore primary inoculum production and susceptible leaf tissue emergence in spring is thus critical in this pathosystem, conditioning the initiation of epidemics each year. Oak-fungus phenological synchrony clearly illustrates the 'encounter filter' of host-parasite interactions (sensu Combes, 2001; Figure.15.4). By using an altitudinal temperature gradient, we have shown that (1) both fungus (ascospore release) and oak (budburst) phenologies respond to temperature; (2) their responses are different, leading to differences in the phenological match between budburst and the presence of ascospores across altitudes; (3) oak phenology is a potential determinant of disease severity at the end of the growing season, in particular with early flushing trees at low altitudes likely to escape infections whereas late trees had a significantly higher percentage of their leaf area infected (Desprez-Loustau et al., 2010; Dantec et al., 2015).

Unlike oaks, which display local adaptation for phenology within Europe (Ducousso et al., 1996), no differentiation between European populations of Erysiphe alphitoides was detected in terms of the phenology of ascospore production (Marçais et al., 2009). It is possible that the fungus has not had time to adapt to the local climate as it has only been present in Europe for a century. However, the pathogen was found to show patterns of local adaptation at individual host tree level in terms of infection success over the same period (Roslin et al., 2007; Desprez-Loustau et al., 2011). The plasticity in powdery mildew phenology and the high local diversity of oak phenology may account for a relatively weak selection pressure on fungus phenology. 


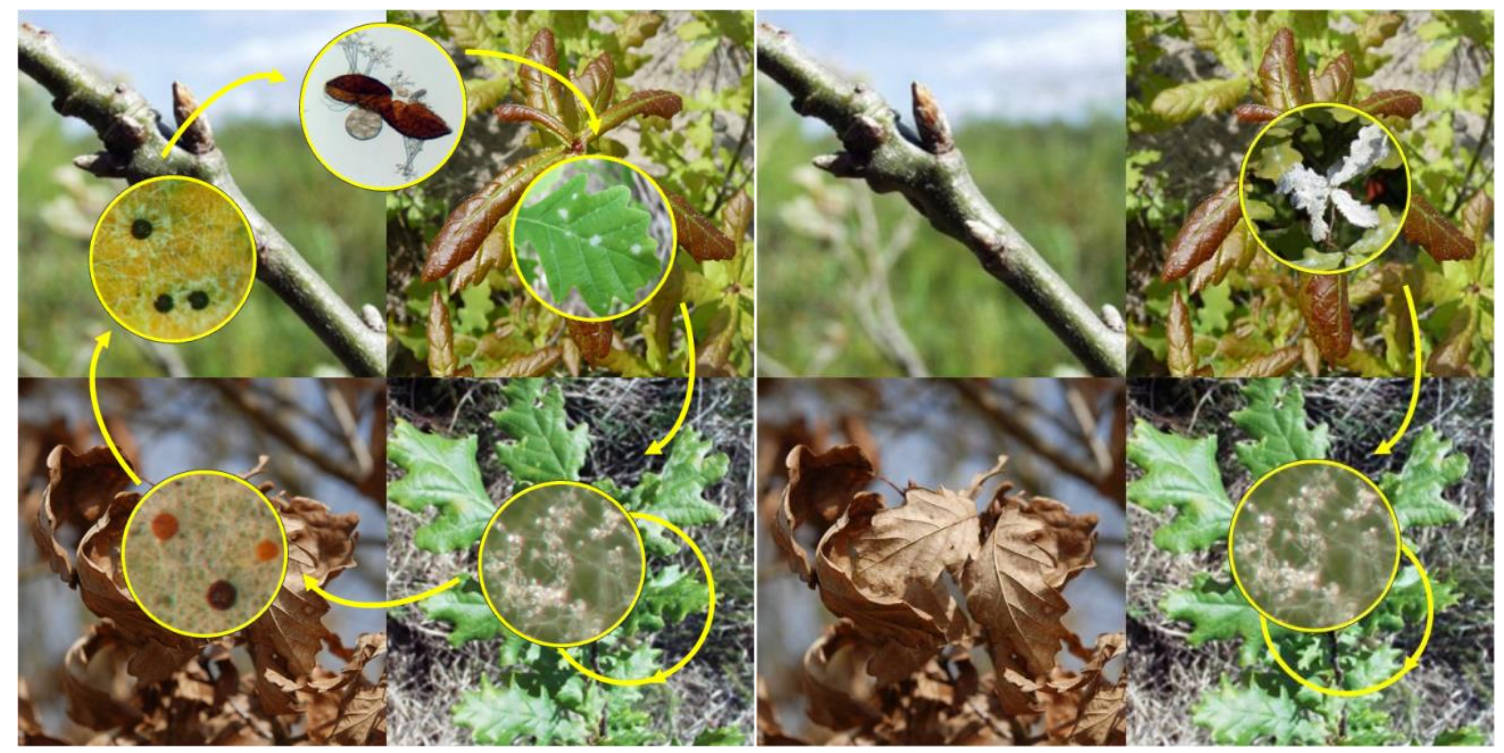

Figure 15.4 Oak powdery mildew life cycle. Powdery mildews are obligate biotrophic parasites, i.e. they cannot live without their host and they derive their energy from living cells. Most of the fungal development is epiphyllous, the only structures within plant tissues being the intra-cellular haustoria which absorb nutrients from the host. Left, complete life-cycle with sexual reproduction: in autumn (lower left), sexual fruiting bodies (chasmothecia) are formed on infected leaves; during winter, the chasmothecia remain dormant; in spring, the ascospores within the chasmothecia are released and airborne; primary infections result from the germination of ascospores on young susceptible leaves which produce colonies of epiphyllous mycelium bearing conidia (asexual spores); during the growing season (spring-summer), several cycles of secondary infections are produced by conidia; Right, alternative cycle without sexual reproduction: mycelium and conidia overwinter in dormant buds (under bud scales), infected buds produce "flag shoots" and conidia produce secondary infections.

\subsection{Epidemiological implications of a pathogen complex.}

The oak powdery mildew pathosystem has an additional layer of complexity, in that the disease is not caused by a single pathogen species but by a complex of closely related species (Figure 15.2).

Using the nuclear ribosomal DNA sequence (a region used as barcode for fungi; Schoch et al., 2012), Takamatsu (2013) and Takamatsu et al. (2015) thoroughly revised the phylogeny of powdery mildews. They showed that at least seven closely related species in the Erysiphe genus, with a common ancestor probably of Asian origin, affect Asian oaks (Limkaisang, et al. 2006; Takamatsu et al., 2007). At the time of oak powdery mildew invasion in Europe, these species were unknown and mycologists initially thought that the pathogen had been introduced from North America, as for grapevine powdery mildew a few decades earlier. However, the morphology of the invasive pathogen differentiated it from all described species known to infect oak, and the fungus was therefore described as the new species $E$. alphitoides. One of the other species in the clade described by Takamatsu et al. (2007), E. hypophylla, was later shown to have spread westwards in Europe in the 1950s-60s (Viennot-Bourgin, 1968, Figure 15.2).

The recently described $E$. quercicola has been shown to occur together with $E$. alphitoides and $E$. hypophylla in France, in addition to Phyllactinia spp which may be an endemic powdery mildew species (Mougou, et al., 2008; Mougou-Hamdane et al., 2010; Figure 15.2). A recent survey showed that $E$. alphitoides predominates in most of Europe, with E. quercicola and E. hypophylla having much lower frequencies and more restricted distributions, towards the south for $E$. quercicola and the north-east for $E$. hypophylla. However, the different species can co-occur in a single region, stand, tree, leaf and even lesion (Mougou-Hamdane, et al. 2010; Marçais, et al., 2017). 
Box 15.1: Seasonality, semi-discrete epidemic models, and the evolution of virulence in plant parasites

We introduce a simple semi-discrete model accounting for seasonality with two types of infected individuals which we then use in two different but related contexts. (i) The two types correspond to different strains of the same species. Under certain conditions, evolution tends to select the strain with the largest reproductive number, and we discuss the implications of climate change (e.g. increasing season length) for the evolution of virulence in plant parasites. Under broader conditions, evolutionary branching may occur, leading to dimorphism in the parasite population. (ii) The two types are then assumed to correspond to different parasite species. We show that the two species can coexist in the long run while exploiting the same resource, contradicting the competitive exclusion principle (Armstrong \& McGehee, 1980).

Model

For simplicity, we assume that total host density is constant throughout the season. Let $S, I$, and $R$ be the densities of susceptible, infected, and removed (e.g. defoliated) hosts, respectively. In addition, let $I=I_{1}+I_{2}$ with $I_{1}$ and $I_{2}$ representing hosts infected with type 1 and by type 2 parasites, respectively (for simplicity, we ignore multiple infections at the host scale chosen, e.g. the leaf). Let $T$ be the duration of an annual cycle (one year), and $k$ be a cycle index. Also, let $\tau$ be the length of the season. Let $\beta_{1}$ and $\beta_{2}$ be the secondary infection rates associated with type 1 and type 2 parasites, respectively. Similarly, let $\alpha_{1}$ and $\alpha_{2}$ be the disease-induced removal rate (virulence) associated with type 1 and type 2 parasites, respectively.

During the season, i.e. for all $t$ between $k T$ and $k T+\tau$, the epidemiological dynamics are described by an SIR model (Kermack \& McKendrick, 1927; Segarra et al., 2001). For $i=1,2$, the model reads

$$
\begin{aligned}
& \frac{\mathrm{d} S}{\mathrm{~d} t}=-S\left(\beta_{1} I_{1}+\beta_{2} I_{2}\right), \\
& \frac{\mathrm{d} I_{\mathrm{i}}}{\mathrm{d} t}=I_{\mathrm{i}}\left(\beta_{\mathrm{i}} S-\alpha_{\mathrm{i}}\right) .
\end{aligned}
$$

From season to season, i.e. from $k T+\tau$ to $(k+1) T$, the dynamics are described by a discrete-time model. Let $S_{0}$ be the initial susceptible host density (which is assumed to be renewed each year regardless of disease incidence) and $\chi$ be a composite parameter aggregating survival forms production per infected leaf, survival probability, and primary infection rate (Mailleret et al., 2012). This parameter is specific to each type of parasite, and $\chi_{i}$ will be referred to as the between-season transmission 
parameter associated with type $i$. Assuming that primary infections occur over a shorter timescale than secondary infections, we consider: for $i=1,2$,

$$
\begin{aligned}
& S((k+1) T)=S_{0} \exp \left(-\sum_{j=1}^{2} \chi_{j} \mathrm{I}_{j}(k T+\tau)\right), \\
& I_{i}((k+1) T)=S_{0}\left(1-\exp \left(-\sum_{j=1}^{2} \chi_{j} I_{j}(k T+\tau)\right)\right) \times \frac{\chi_{i} I_{i}(k T+\tau)}{\sum_{j=1}^{2} \chi_{j} I_{j}(k T+\tau)} .
\end{aligned}
$$

The exponential term represents the probability of a susceptible leaf escaping primary infection. The fraction represents the probability of infection with species $i$ given that infection occurred (Hamelin et al., 2011). The annual cycle repeats. Figure B15.1.1 illustrates the model. Table B.15.1.1 provides a list of the parameters and variables for equations (15.1) and (15.2).

Evolutionary invasion analysis

Let $I_{1}$ be a resident monomorphic population challenged by a small mutant subpopulation $I_{2}$. Assuming that the resident population is at ecological

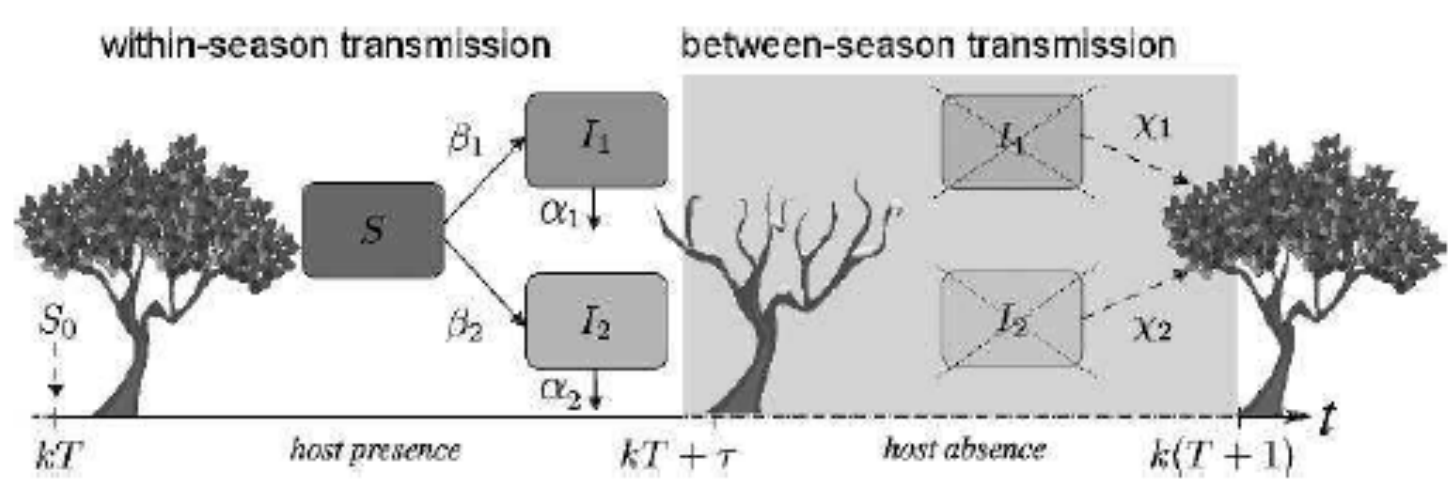

Figure B15.1.1 Flow-chart of the model associated with equations (15.1) and (15.2). At the beginning of the season $\left(t=k T\right.$ ), a density $S_{0}$ of susceptible hosts (e.g. green leaves) is made available to the parasites. Susceptible hosts can be infected by type 1 or type 2 parasites. The within-season transmission rates of type 1 and type 2 parasites are $\beta_{1}$ and $\beta_{2}$, respectively. The hosts infected by type 1 and type 2 are continuously removed (e.g. defoliated) from the system at rates $\alpha_{1}$ and $\alpha_{2}$, respectively. At the end of the season (time $t=k T+\tau)$, both susceptible and infected hosts are removed (e.g. leaves fall to the ground) and the parasites switch to survival forms (e.g. free-living spores). At the beginning of the next season (time $t=k(T+1)$ ), survival forms generate new infections. The between-season transmission rates of type 1 and type 2 parasites are $\chi_{1}$ and $\chi_{2}$, respectively. Solid and dashed lines correspond to discrete- and continuous-time processes in the model, respectively. 
Box 15.1: (cont.)

Table B15.1.1 Model parameters and variables

\begin{tabular}{lll}
\hline Parameter & Variable & Units \\
\hline Length of the season & $\tau$ & [time] $(\leq 1 a)$ \\
Length of the off-season & $T-\tau$ & [time] $(\leq 1 a)$ \\
Within-season transmission rates & $\beta_{1}, \beta_{2}$ & [space/time] \\
Between-season transmission parameters & $\chi_{1}, \chi_{2}$ & [space] \\
Infected leaf removal rate & $\alpha_{1}, \alpha_{2}$ & {$[1 /$ time] } \\
Initial and maximum host density & $S_{0}$ & {$[1 /$ space] } \\
\hline
\end{tabular}

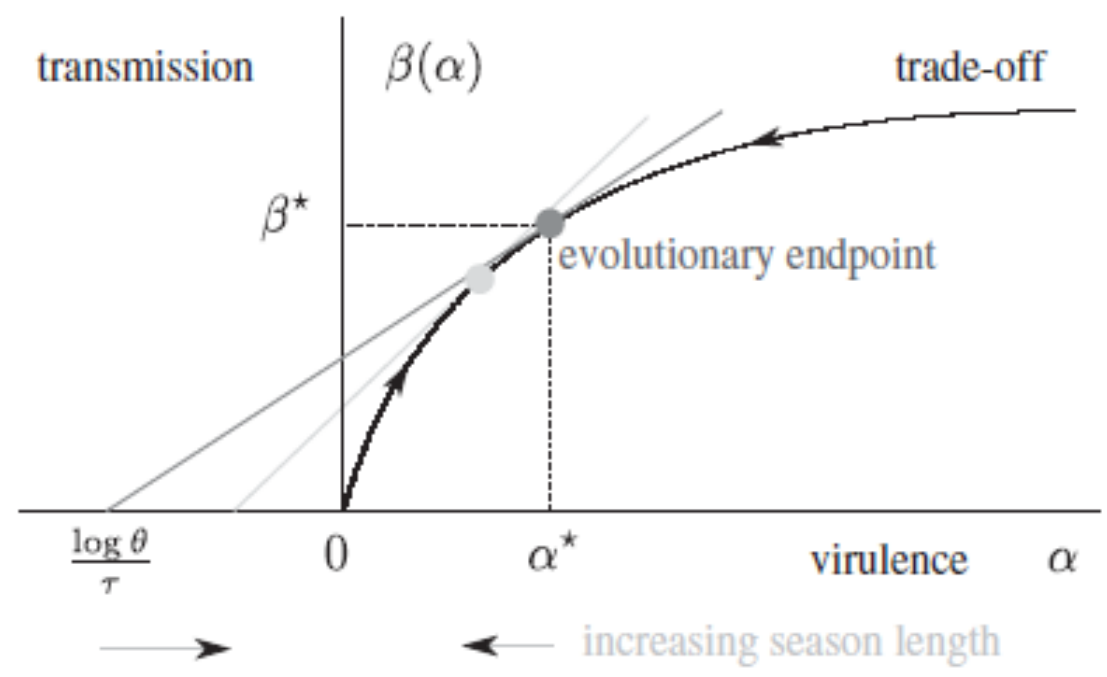

Figure B15.1.2 Classical graphical solution of the optimal virulence strategy, maximising the basic reproductive number, for a possible trade-off between transmission and virulence (black solid curve). The differentiation of $R_{0}$ with respect to alpha indicates that the optimum is the point at which the dark grey tangent line passes through the point $(\log (\theta) / \tau, 0)$ (Alizon et al., 2009; van den Berg et al., 2011). The originality here is that $\theta=\chi \mathrm{S}_{0}<<1$ is a season-to-season transmission parameter, and $\tau$ is the length of the season. Hence, increasing the length of the season decreases the evolutionarily stable level of virulence (light grey tangent line).

equilibrium when the mutant is introduced, it can be shown (Hamelin et al., 2011) that the mutant can invade if

$$
\chi_{2} \exp \left(\left[\beta_{2} \overline{S_{1}}-\alpha_{2}\right] \tau\right)>\chi_{1} \exp \left(\left[\beta_{1} \overline{S_{1}}-{ }_{1}\right] \tau\right),
$$

where $\overline{S_{1}}$ is the mean healthy host density at the equilibrium corresponding to the resident parasite population. This quantity depends on $\left(\alpha_{1}, \beta_{1}, \chi_{1}\right)$, but no explicit expression of $\overline{S_{1}}$ is known. 


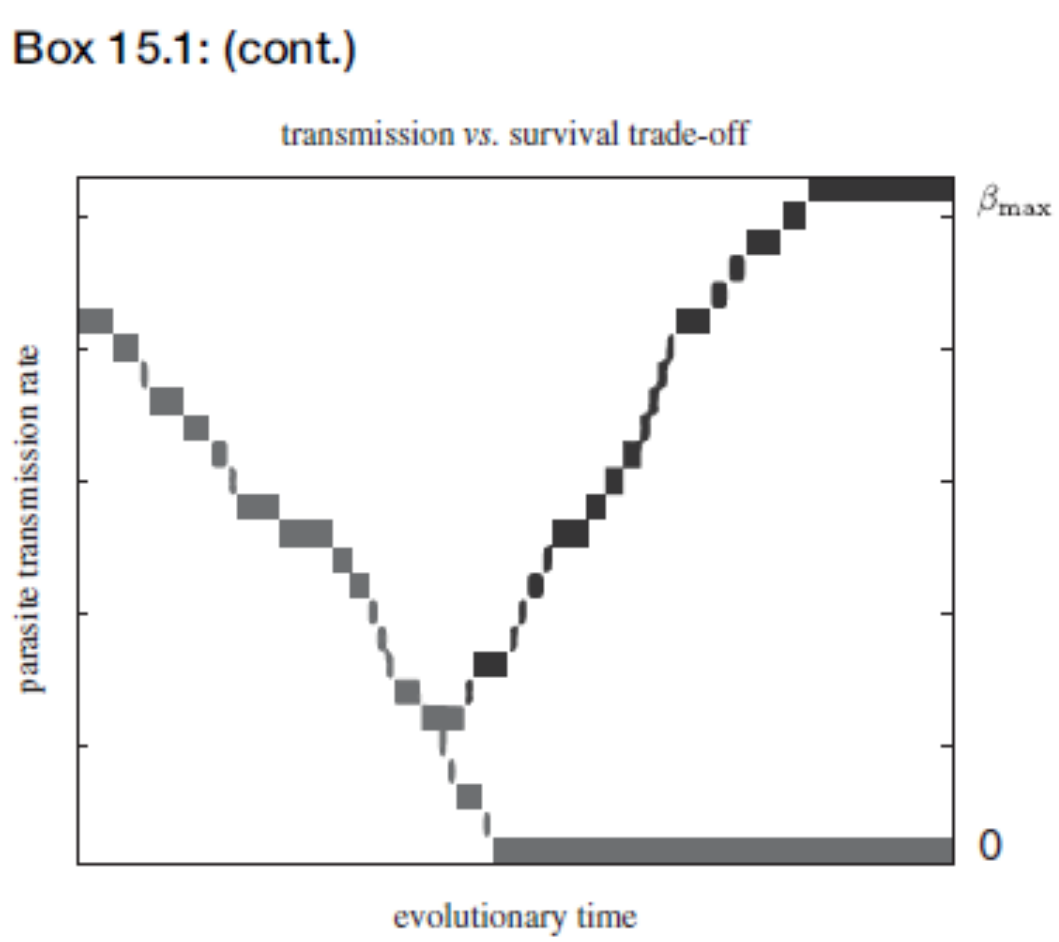

Figure B15.1.3 Evolutionary dynamics associated with model (1-2) assuming a trade-off between within-season and between-season transmission (adapted from figure 2 in Hamelin et al., 2011). There is initially one ancestral parasite type. The mutation-selection process first selects for decreasing within-season transmission (thus increasing between-season survival), and subsequently splits the parasite population into two types, one specialising in within-season transmission, and the other in between-season transmission. The ecological dynamics and the parameter values corresponding to this dimorphic evolutionary endpoint are shown in Figure B15.1.4. (A black and white version of this figure will appear in some formats. For the colour version, please refer to the plate section.)

Considering a trade-off between transmission and virulence ( $\beta$ versus $\alpha$ ), a simplification occurs for small $\chi$ values. Let $\beta(\alpha)$ represent the trade-off function, which is increasing and concave (Figure B15.1.2). In this case, it can be shown (van den Berg et al., 2011; Mailleret et al., 2012) that evolution selects the value of $\alpha$ maximising the basic reproduction number of the parasite:

$$
\mathrm{R}_{0}=\frac{\beta(\alpha) \mathrm{S}_{0}}{\alpha-\frac{\log (\theta)}{\tau}}
$$

where $=\chi S_{0} \ll<1$. Interestingly, increasing the length of the growing season $\tau$ decreases the evolutionarily stable virulence, maximising $R_{0}$ (Figure B15.1.2). This is because increasing the season length increases the possible gain of parasite fitness associated with host longevity. 
Box 15.1: (cont.)

a
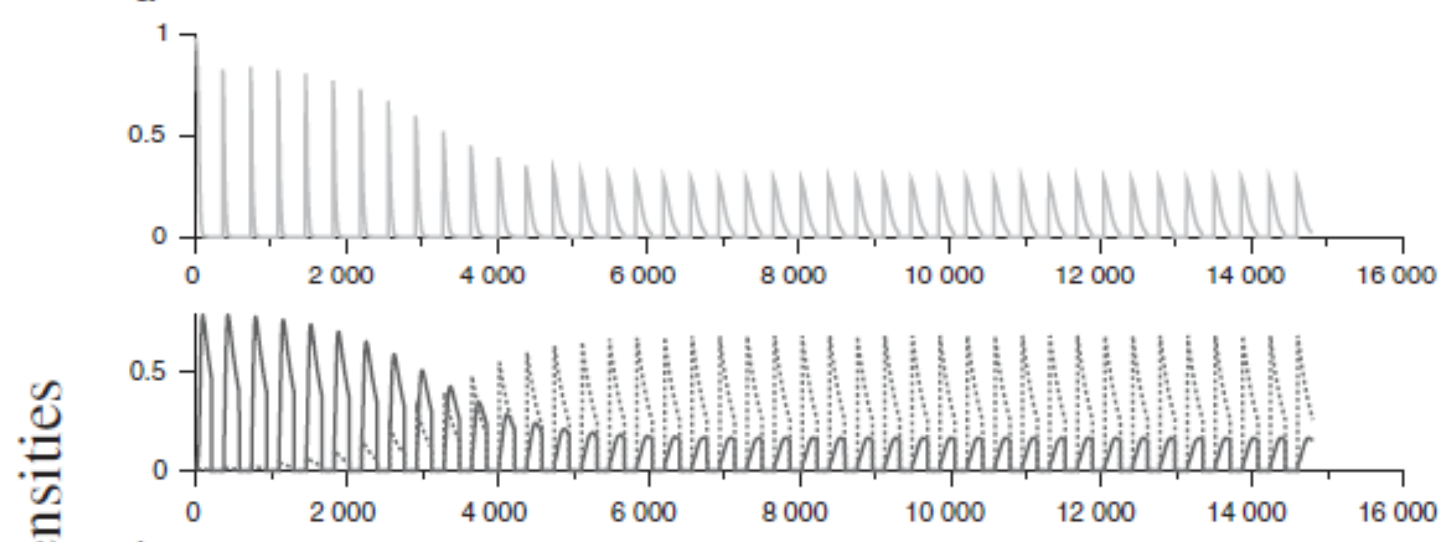

b
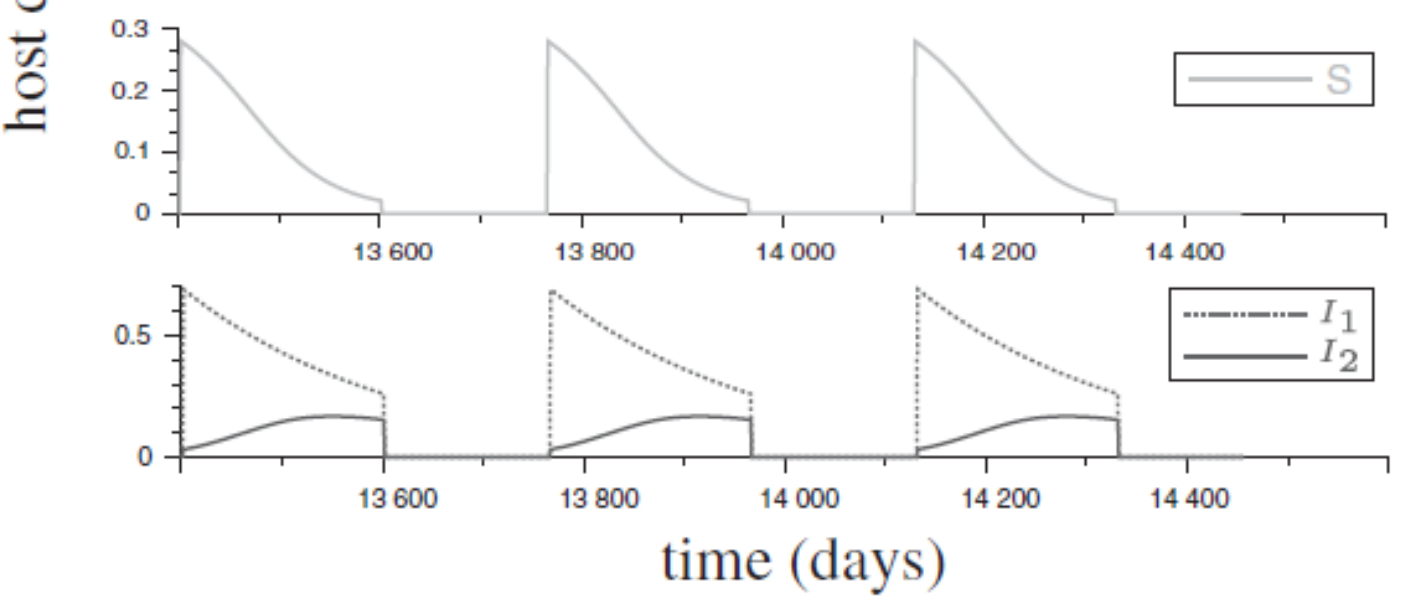

Figure B15.1.4 Long-term coexistence of two parasite species subject to periodic absence of the host plant (adapted from figure 1 in Hamelin et al., 2016). (a) Infected plant densities $I_{1}$ and $I_{2}$ as a function of time, for $k=40$ cycles (years). (b)Zoom on the last three cycles. Parametervalues: $\alpha_{1}=\alpha_{2}$ $=0.005, \beta_{1}=0.1, \beta_{2}=0.001, \chi_{1}=0.369, \chi_{2}=4.68, T=365, \tau=200$, and $S_{0}=1$ (without loss of generality). (A black and white version of this figure will appear in some formats. For the colour version, please refer to the plate section.)

Considering a trade-off between in-season and between-season transmission $(\beta$ versus $\chi$ ) yields different evolutionary outcomes. Starting from a monomorphic population, evolutionary branching may lead to a stable dimorphism in the population: one type specialises on within-season transmission whereas the other type specialises on between-season transmission (Hamelin et al., 2011; Figure B15.1.3).

Long-term coexistence of two parasites exploiting the same plant host A trade-off between within-season and between-season transmission can thus lead to long-term coexistence of two parasite species. Moreover, the two species may significantly overlap in time without compromising their coexistence 
(Kisdi, 2012). For instance, Figure B15.1.4 shows model dynamics for a parameter set enabling the two species to coexist (Mailleret et al., 2012; Hamelin et al., 2016). A fast outbreak of type 1 at the beginning of the season leaves enough susceptible hosts for a second outbreak of type 2 because type 2 has a greater within-season transmission rate than type 1 . However, type 2 has a lower between-season transmission rate than type 1 , which is at an advantage during the primary infection phase at the beginning of the next season. Thus, type 2 does not interfere with the early outbreak of type 1 , and both parasite species succeed and coexist on a single host plant.

The existence of pathogen complexes in both the putative region of origin and the invaded area raises several questions. The co-occurrence of closely related pathogen species exploiting the same host plant apparently challenges the competitive-exclusion principle (Amarasekare, 2003). Can timepartitioning account for this co-existence (Loreau, 1992; Chesson, 2000)? From an epidemiological perspective, could temporal differences between the pathogens result in greater host damage due to more complete resource exploitation? Such a complementarity effect between species has rarely been considered for pathogens but is one of the mechanisms underlying the well-established positive relationship between plant species richness and ecosystem productivity (Loreau \& Hector, 2001).

From mathematical analysis and numerical simulation of semi-discrete models including seasonality, van der Berg et al. $(2010,2011)$ concluded that a trade-off between pathogen transmission rate and survival between cropping seasons could not account for the evolutionary branching observed in many plant pathogens. However, Hamelin et al. (2011) and Mailleret et al. (2012), revisiting this issue with the same type of model and further analysis, showed that evolutionary branching and coexistence through temporal niche partitioning might be biologically possible. Moreover, Hamelin et al. (2016) showed that coexistence may not be only possible but also, plausible as it can occur in a significant part of the parameter space of the model. Models also predict that the most frequent species at the beginning of the season may become the least frequent by the endwithout compromising the long-term coexistence of the two species. Hence, the existence of a trade-off between in-season and off-season transmission may allow sibling plant pathogens to coexist, with some species performing mainly as primary infectors (with high levels of inter season transmission) and others mainly as secondary infectors (with a large capacity to generate secondary cycles of infection within a season).

This generic model nicely fits several plant pathosystems in which pathogens belong to a complex of cryptic species (or lineages) with various modes of overwintering and differing in temporal dynamics (Fitt et al., 2006; Montarry et al., 2008). A similar situation applies to oak powdery mildew for which the two most frequent species in France, E. alphitoides and E. quercicola, produce similar symptoms on leaves but overwinter in different ways. Up to now, chasmothecia have been strictly associated with $E$. alphitoides. Conversely, recent collections of flag shoots (presumably associated with hibernating colonies of oak powdery mildew in buds) yielded only E. quercicola (Feau et al., 2012), although flag shoots were commonly reported in the years following invasion by $E$. alphitoides (Woodward, 1929; Kerling, 1966). Similar differences in the mode of overwintering have been reported in the putative native area in Asia, with E. alphitoides often forming chasmothecia whereas $E$. quercicola seems to overwinter preferentially in buds, although this species has occasionally been reported to form chasmothecia in this region (Takamatsu et al., 2007). The difference in the mode of winter survival between $E$. alphitoides and $E$. quercicola results in different temporal dynamics in spring at a given site: E. quercicola appears first in the season (in the form of flag shoots just after budburst), but its relative frequency decreases over time, and $E$. alphitoides is dominant at most sites by the end of the season (Feau et al., 2012). The generic seasonal model of Hamelin et al. (2011) provides a satisfactory 
fit to the joint dynamics of the two oak powdery mildew cryptic species (Figure 15.5); parameter estimation suggests that $E$. alphitoides has a higher secondary infection rate and lower betweenseason transmission rate than E. quercicola (Hamelin et al., 2016).

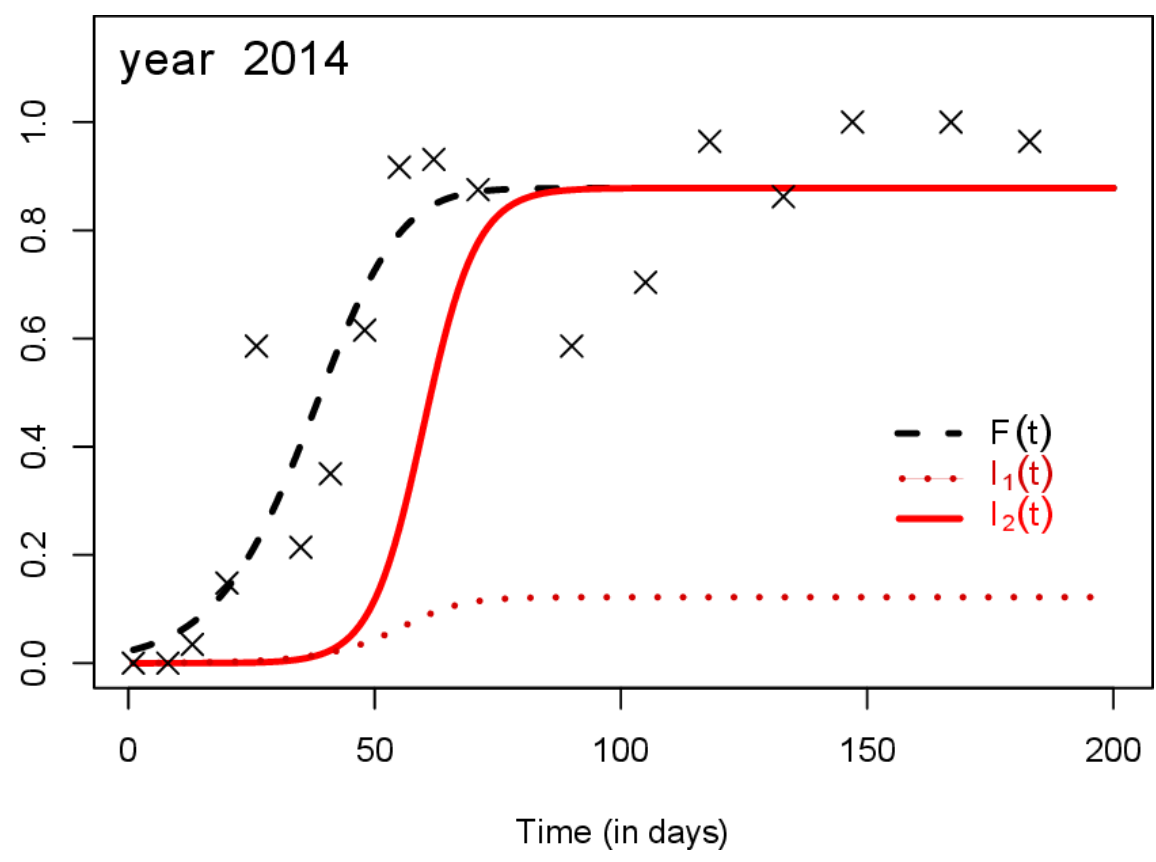

Figure 15.5 Fitting of a semi-discrete epidemiological model with seasonality to empirical data for Erysiphe alphitoides and E. quercicola temporal dynamics, through a maximum-likelihood method (see Hamelin et al., 2016). The dashed curve represents the frequency of species 2 ( $E$. alphitoides) relative to that of species 1 (E. quercicola), i.e. $\mathrm{F}=12 /(\mathrm{I} 1+\mathrm{I} 2)$, as fitted to the data (represented by crosses). The dotted and solid curves represent the associated (inferred) densities of species 1 ( $E$. quercicola) and species 2 (E. alphitoides), respectively.

The possible effects of co-infection on disease dynamics and impact, and on pathogen evolution, have recently attracted attention (e.g. Alizon et al., 2013), including for plant pathosystems. However, the effects of multiple infections on disease severity outcome and pathogen transmission are difficult to predict because mechanisms of interaction between pathogenic strains may be direct or indirect (acting through the host), and may act in opposite directions: synergistic or antagonistic interactions, complementarity effects, cross protection, etc. (Susi et al., 2015; Tollenaere et al., 2016). Moreover, the severity and impact of co-infections may be context-dependent, varying with the effects of environmental conditions on each pathogen (Bearchell et al., 2005; Fitt et al., 2006). In a large survey across France, we tested the hypothesis that $E$. alphitoides and E. quercicola occurrence in the same plot would cause greater disease severity, due to temporal complementarity with E. quercicola principally affecting the first flush of oak leaves and E. alphitoides the second. However, no such effect was shown at the host population scale, with disease severity being primarily explained by the prevalence of the most virulent species E. alphitoides (Marçais et al., 2017).

\subsection{Intrinsic resistance and phyllosphere microbial interactions.}

In the dynamic interplay between hosts and parasites, not only virulence levels change, but resistance would be expected to evolve in the host population. However, genetic changes in long-lived species such as trees are expected to be slow, extending over long evolutionary time scales incompatible with responses to invading pathogens. Nevertheless, large populations of forest trees often display considerable variation in disease susceptibility, even to pathogens that they have not coevolved with. For most epidemics, a small percentage of trees display significant levels of resistance (Ennos, 2015; Budde et al., 2016). In the current epidemic of ash dieback in Europe, 1-5\% of trees in all populations studied display high levels of genetic resistance, indicating that natural (or artificial) selection for much higher levels of resistance should be possible (Budde et al., 2016). Such pre-existing or "serendipitous 
resistance" (Burdon et al., 2013) may result from evolution under the influence of other selective pressures, i.e. exapted resistance. For example, disease resistance may be related to phenological traits selected under abiotic pressure or may have evolved in response to native pathogens resembling the introduced one (Newcombe, 1998; Budde et al., 2016).

The oak powdery mildew pathosystem has several characteristics that might favour evolution of resistance in oak populations, particularly during the period following the introduction of this pathogen into Europe. First, like many forest trees, oaks produce a large number of offspring (at least in mast years), and disease impact is highest at the seedling stage. Disease resistance is thus expected to be an important determinant of fitness at a stage when competition among individuals is strong. Several authors in the early twentieth century reported very high seedling mortality rates in areas invaded by the pathogen (Marçais \& Desprez-Loustau, 2014). Recent studies based on exclusion experiments (using fungicides) and dendrochronological approaches demonstrated fitness costs of infection in the form of growth loss or mortality (Desprez-Loustau et al., 2014; Marcais \& Desprez-Loustau, 2014; Bert et al., 2016). Second, pathogen pressure acts on populations displaying high levels of individual variation in disease-related traits (Desprez-Loustau et al., 2014; Bert et al., 2016). Moreover, this variation is genetically determined (Desprez-Loustau, et al. 2014) with moderate to high heritability estimates (ranging from 0.38 to 0.66 ) when comparing descendants in a single pedigree (Bartholomé et al., unpublished). QTL analyses have identified several candidate disease resistance loci in $Q$. robur (Bartolomé et al., unpublished).

The evolution of disease resistance is also dependent on phenotypic and genetic correlations between traits which will ultimately determine the resistance-fitness relationship. For example, Dantec et al. (2015) showed that the phenology-fitness relationship was opposite under exposure to powdery mildew or frost. Furthermore, the evolution of disease resistance may interact with disease tolerance, i.e. mechanisms that do not limit infection, but reduce its negative consequences on host fitness (Roy \& Kirchner, 2000). Tolerance to damage is related to plant vigour (Weis et al., 2000) and may play a key role in the outcome of infections, as long recognized for plant-herbivore interactions (Baucom \& de Roode, 2011). Our results suggest that tolerance, positively correlated with growth potential, might overcome resistance effects on fitness, assessed by oak seedling survival under natural infection (Desprez-Loustau et al., 2014). Testing for an increase in resistance in oak populations since the introduction of powdery mildew would require comparing levels in pre- and post-invasion oak populations. Very old trees that are still alive and were already mature when invasion occurred in the early twentieth century (i.e. older than 150 years) may be considered representative of pre-epidemic populations, since mortality at the time of invasion was mostly reported for seedlings and young trees, and not for mature trees in high forests (Viney, 1970). Comparisons of the susceptibility to disease of the offspring of these trees, to that of trees from younger cohorts (subject to pathogen selection pressure as juveniles), may provide an indication of the selective forces at work.

The microbial community living in association with trees, particularly in the phyllosphere, may also influence the potential of tree populations to cope with emerging diseases (Budde et al., 2016); there is increasing evidence for its potential role in mediating susceptibility or resistance to disease (e.g. Berendsen et al., 2012; Busby et al., 2016). Moreover, as microbial communities are highly dynamic over time, they may supply the plant with a defence arsenal evolving at the same pace as pathogens. This could play a critical role in long-lived species such as trees, which are exposed to a great diversity of pathogens during their life-time (Lively et al., 2014; Budde et al., 2016). Jakuschkin et al. (2016) have shown that $E$. alphitoides is involved in a complex network of interactions in the phyllosphere. Their study, combining metabarcoding and network inference methods, demonstrated that infection with E. alphitoides was accompanied by significant changes in the composition of the foliar fungal and bacterial communities. Several potential bacterial and fungal antagonists to $E$. alphitoides were identified.

Interestingly, the involvement of an antagonist in the decline of the disease was first suggested early in the years following the oak powdery mildew invasion in Europe. Vuillemin (1910b) observed that the powdery mildew fungus was itself parasitised by another fungus, from the genus Cicinnobolus, and he suggested that this hyperparasite might be acting as a natural regulatory agent of the disease. These observations are consistent with the "pathogen accumulation hypothesis" proposed for long-term decline in the density and distribution of some invasive species (generally plants; Flory \& Clay, 2013). 
Ampelomyces quisqualis, previously known as Cicinnobolus cesatii, was described from infected grapevine leaves a few years after the appearance of grapevine powdery mildew in Europe in the 1850s (Emmons, 1930; Kiss et al., 2004). We have detected $A$. quisqualis in oak powdery mildew lesions all over Europe but its impact on disease epidemiology remains to be investigated.

\subsection{Future prospects.}

Several developments are likely to increase our understanding of the pathosystem and help predict its future trajectory, involving the combination of various modelling approaches and the acquisition of empirical data guided by theory.

\subsubsection{Disease modelling over multiple growing seasons, including climate effects.}

The development of models capturing the long-term behaviour of pathosystems over multiple growing seasons, including temporal changes in host availability and pathogen overwintering (particularly for perennial hosts), has been identified as a key challenge in plant epidemiology (Cunniffe et al., 2015). Our semi-discrete model provides a generic approach to this issue. Its application to oak powdery mildew highlights the need to explore transmission-virulence and transmission-survival trade-offs to improve predictions of the effects of climate change, through increases in growing season duration, on the pathosystem.

Virulence-transmission trade-offs have rarely been estimated for plant pathogens (Doumayrou et al., 2013; Pasco et al., 2016); an alternative could be to study fitness as a function of virulence (Alizon \& Michalakis, 2015). Assessing pathogen fitness and virulence is not straightforward (Gilchrist et al., 2006; Alizon et al., 2009), but they could be measured at leaf level for oak powdery mildew. We may consider fitness as the total production of spores (i.e. the product of leaf life-span and spore production per day), and virulence as the decrease in leaf life-span. Several isolates should then be compared to determine whether the fitness-virulence function peaks at an intermediate virulence level. Furthermore, a possible partial virulence-overwintering trade-off could be investigated by quantifying the production of chasmothecia by isolates from different climates. However, assessing the between-season transmission parameter (Chi in Box 15.1) would also require the quantification of pathogen winter survival, primary inoculum production in spring and the success of primary infections.

As described above, primary infection success is governed by good phenological synchrony between host and pathogen, determined largely by the plastic response of both pathogen and host to environmental cues (especially temperature; Desprez-Loustau et al., 2010; Altizer et al., 2013). Available data for fungal ascospore and oak budburst timings (Marcais et al., 2009; Vitasse et al., 2011) should make it possible to adjust semi-mechanistic models of phenology, based on chilling and forcing phases driven by temperature (Chuine et al., 2013), to simulate phenological synchrony over space and time (including for climate change scenarios). Disease data from the Forest Health Service database (Marçais \& Desprez-Loustau, 2014) could be used to validate this synchrony index as a predictor of disease severity. Climate change is also likely to affect disease dynamics within the growing season, through effects on parasite performance and host immunity. Linking epidemiological models with the metabolic theory of ecology (Brown et al., 2004) is a promising approach to addressing this question (Altizer et al., 2013); applying this theory to the oak powdery mildew system provides an exciting framework for empirical studies.

\subsubsection{Integrating tree population dynamics through age-structured modelling.}

Our semi-discrete model (Box 15.1) includes the default assumption of constant host population size within and between seasons. An obvious improvement would be to incorporate host growth dynamics (Van den Berg et al., 2011; Cunniffe et al., 2015). In oaks, which display polycyclic shoot growth, withinseason growth dynamics are characterised by the occurrence of successive flushes of new shoots separated by resting phases within the same vegetative period (Verdu \& Climent, 2007). The continuous phase of our model could, therefore be split into several phases. However, most mature trees have only two flushes. The first flush is mostly infected by the primary inoculum whereas subsequent cycles of secondary inoculum infect the second flush. Thus, our model with two different transmission parameters for primary and secondary inoculum captures the within-season dynamics to some extent. 
Future models could include oak demography by distinguishing between juvenile and mature stages. Indeed, seedlings and trees differ in many traits likely to affect disease dynamics, such as: phenology (Vitasse, 2013); polycyclism, which is more marked in seedlings, with up to four or five flushes (Desprez-Loustau et al., 2014); height, which has been shown to have a strong influence over the likelihood of flag shoots being produced, and thus between-season transmission (Marçais et al., 2017); and possibly leaf traits that could affect within-season transmission. Spatial structure also differs considerably between the juvenile and mature stages (with very high densities at the seedling stage) and this will likely affect dispersal-transmission. In particular, auto-infection (i.e. caused by inoculum produced on the same plant) would be expected to increase strongly between the seedling and mature stages, with increasing host genotype area and decreasing host density. This prediction is consistent with observed patterns of oak powdery mildew adaptation at tree level (Roslin et al., 2007), and similar observations for oak insect herbivores supporting the adaptive deme formation hypothesis (Zandt \& Mopper, 1998).

\subsubsection{From a simple binary interaction to a network of interacting species.}

The questions of evolutionary branching and the coexistence of cryptic pathogen species could also be explored with this new seasonal model including oak population dynamics (juvenile and mature oaks) and transmission-survival trade-off, and also with the virulence-transmission trade-off which was not considered previously (Hamelin et al., 2011). Available data strongly suggest differences in the distribution patterns of $E$. alphitoides and $E$. quercicola between seedlings and trees in the same stand (unpublished data). Differences between seedlings and trees may also influence the infection of oak powdery mildew fungi with the mycoparasite $A$. quisqualis (e.g. through dispersal and microclimate), to which $E$. alphitoides and $E$. quercicola may not be equally susceptible. Incorporating the tritrophic interaction into the host structured semi-discrete model could be easily tested with observational data.

Our model can currently simulate several pathogen species but it includes only one host species. However, like many plant pathogens, E. alphitoides and E. quercicola can infect several species (including $Q$. petraea and $Q$ robur, the most common oaks in Europe). Potential differences in virulence and transmission according to host and pathogen species, as well as relative host densities, are critical for eco-evolutionary disease dynamics (Cunniffe et al., 2015). Species diversity in both hosts and pathogens is likely to affect competition relationships at both levels and the evolution of pathogen virulence and host resistance. Plant pathologists have shown great interest in these questions at the infra-specific level, focusing on the evolution of pathogen populations in host cultivar mixtures, mostly with a gene-for-gene model underlying strict host specificity (Jeger, 2000). Much less attention has been paid to this issue in diverse wild plant communities (Bever et al., 2015). Differences in susceptibility to powdery mildew between oak species have been reported. In particular, $Q$. pyrenaica has been reported to suffer the highest mortality in early epidemics, and $Q$. robur appears to be slightly more susceptible than Q. petraea (Marçais \& Desprez-Loustau, 2014). Reciprocally, E. alphitoides and E. quercicola seem to display some differences in Quercus host species preference (Takamatsu et al., 2007), including in Europe (Marçais et al., 2017; unpublished data). Oak powdery mildew may therefore be an important driver of the joint dynamics of the different oak species occurring together in mixed stands in many areas across Europe, and may affect the many ecosystem services they provide.

\subsubsection{Evolution of oak resistance and tolerance: growth-defence relationships.}

A key concept in plant defence theory, based on considerations of the cost of resistance, is the growthdefence trade-off hypothesis (Brown, 2003; Huot et al., 2014). However, its generality still requires empirical support. An immuno-ecological approach, with experiments using oak genotypes under various levels of resource supply and pathogen pressure, could inform on phenotypic plasticity of defence investments and on relationships between defence and growth in the oak powdery mildew pathosystem. However, no oak material is yet available for direct estimation of the cost of single genes, as was done in Arabidopsis using isogenic lines (Tian et al., 2003). Modelling the evolution of host resistance through a growth-defence trade-off, either in the short term (same temporal scale as the pathogen cycle, with resistance mediated by the microbiota) or in the longer term (adaptive evolution of the host through an increase in intrinsic resistance) would be novel in the framework of semi-discrete models. 
An alternative or complementary approach would be to use a stochastic individual-based, genetically explicit simulation framework such as Nemo (Guillaume \& Rougemont, 2006) or Metapop (Soularue \& Kremer, 2012). For example, disease and resistance evolution could be simulated on landscapes heterogeneous for climate (temperature) and resource availability. Environmental factors would condition tree fitness through a survival-defence trade-off associated with phenology (Dantec et al., 2015) and a growth-defence trade-off. In contrast to defence, growth rate can be positively related to tolerance, with very different epidemiological and evolutionary outcomes (Roy \& Kirchner, 2000; Best et al., 2014; Cronin et al., 2014). Exploring how these two strategies have evolved in the oak powdery mildew pathosystem, both from observations and modelling, is a very interesting avenue of research.

Rapid progress in the acquisition of genomic resources for both oaks (Plomion et al., 2016) and powdery mildew should soon facilitate investigations of co-evolutionary and co-adaptation dynamics in this pathosystem. In particular, the recent release of a draft genome sequence of $E$. alphitoides (Dutech et al., unpublished) provides valuable genomic resources to identify molecular markers for population genetic and phylogeographic studies. Studies based on living and herbarium specimens and Bayesian analyses will make it possible to reconstruct the invasion history of the three Erysiphe species, in particular to give further support or not to the hypothesis of an introduction from Asia. Whole-genome approaches in both powdery mildew and oak will also make it possible to study selection patterns at gene level and to disentangle adaptation processes in the host-pathogen interaction. Population genomic studies of powdery mildew on different hosts and at different geographic locations, and reciprocally of oaks in different regions or at different times (historical samples) likely to be subject to different disease pressures, may lead to the identification of 'hot' spots and 'cold' spots of co-evolution in the native and introduced areas.

\subsection{Conclusions.}

The oak powdery mildew pathosystem has displayed dramatic changes over the last century in Europe, from being an emerging disease with pathogen invasion dynamics, causing high damage, towards a new equilibrium with lower levels of damage. Several non-mutually exclusive hypotheses potentially account for the trajectory followed, including a decrease in the virulence of introduced pathogens, a reciprocal increase in the resistance of oak populations, and also effects of biotic (phyllosphere microbes) and abiotic (climate) environmental factors. Understanding the pathosystem requires two important characteristics to be accounted for: seasonality and the occurrence of a pathogen complex with several cryptic species. Observational data strongly suggest that the severity of annual epidemics is linked to between-season transmission of the pathogen, including off-season survival and primary inoculum success in spring. Climate-driven phenological synchrony between host and pathogen thus appears to be crucial. A semi-discrete model accounting for seasonality in the pathosystem can explain the coexistence of cryptic pathogen species with differing within-season and between-season transmission rates.

While emerging diseases caused by invasive pathogens are increasingly frequent in wild populations (e.g. Fisher et al., 2012), mobilizing much research on the outbreak phase, understanding mechanisms explaining long term dynamics of such diseases is also critical. Oak powdery mildew, is a powerful case-study for exploring many questions in theoretical and applied plant epidemiology (Jeger, 2000; Cunniffe et al., 2015) in the wider context of the evolutionary ecology of invasion and disease (Lively et al., 2014).

\subsection{Acknowledgements.}

The authors gratefully acknowledge the special contribution of Cyril Dutech, Dominique Piou, Corinne Vacher, Xavier Capdevielle, Gilles Saint-Jean, Olivier Caël, Olivier Fabreguette and Martine Martin to the research on oak powdery mildew. Funding and cooperation with the French Forest Health Service (Département Santé des Forêts) provided great help. The modelling study benefitted from a grant of the French National Research Agency (ANR) as part of the "Programme blanc 2013" (ANR-13-BSV70011, Funfit project). We thank Andrin Gross for constructive comments on the manuscript and Julie Sappa for English editing. 


\subsection{References}

Aguayo, J., Elegbede, F., Husson, C., Saintonge, F.X. \& Marçais, B. (2014) Modeling climate impact on an emerging disease, the Phytophthora alni induced alder decline. Global Change Biology, 20, 3209-3221.

Alizon, S., Hurford, A., Mideo, N. \& Van Baalen, M. (2009) Virulence evolution and the trade-off hypothesis: history, current state of affairs and the future. Journal of Evolutionary Biology, 22, 245-259.

Alizon, S., de Roode, J. C. \& Michalakis, Y. (2013) Multiple infections and the evolution of virulence. Ecology letters, 16, 556-567.

Alizon, S. \& Michalakis, Y. (2015) Adaptive virulence evolution: the good old fitness-based approach. Trends in Ecology \& Evolution, 30, 248-254.

Altizer, S., Ostfeld, R. S., Johnson, P. T., Kutz, S. \& Harvell, C. D. (2013) Climate change and infectious diseases: from evidence to a predictive framework. Science, 341(6145), 514-519.

Anderson, R. M. \& May, R. M. (1982) Coevolution of hosts and parasites. Parasitology, 85, 411-426.

Amarasekare, P. (2003) Competitive coexistence in spatially structured environments: a synthesis. Ecology Letters, 6 , 1109-1122.

Armstrong, R. A. \& McGehee, R. (1980) Competitive exclusion. The American Naturalist, 115, 151-170.

Baucom, R. S. \& de Roode, J. C. (2011) Ecological immunology and tolerance in plants and animals. Functional Ecology, 25, 18-28.

Bearchell, S. J., Fraaije, B. A., Shaw, M. W. \& Fitt, B. D. (2005) Wheat archive links long-term fungal pathogen population dynamics to air pollution. Proceedings of the National Academy of Sciences of the United States of America, 102, 5438-5442.

Berendsen, R. L., Pieterse, C. M. \& Bakker, P. A. (2012) The rhizosphere microbiome and plant health. Trends in Plant Science, 17, 478-486.

Berngruber, T. W., Froissart, R., Choisy, M. \& Gandon, S. (2013) Evolution of virulence in emerging epidemics. PLoS Pathogens, 9(3), e1003209.

Bert, D., Lasnier, J.-B., Capdevielle, X., Dugravot, A. \& Desprez-Loustau, M. L. (2016) Powdery mildew decreases the radial growth of oak trees with cumulative and delayed effects over years. Plos One, 11(5), e0155344.

Best, A., White, A. \& Boots, M. (2014) The coevolutionary implications of host tolerance. Evolution, 68, 1426-1435.

Bever, J.D., Mangan, S.A. \& Alexander, H.M. (2015) Maintenance of Plant Species Diversity by Pathogens. Annual Review of Ecology, Evolution, and Systematics, 46, 305-325.

Brown, J. K. (2003) A cost of disease resistance: paradigm or peculiarity? Trends in Genetics, 19, 667-671.

Brown, J. H., Gillooly, J. F., Allen, A. P., Savage, V. M. \& West, G. B. (2004) Toward a metabolic theory of ecology. Ecology, 85, 1771-1789.

Budde, K. B., Nielsen, L. R., Ravn, H. P. \& Kjær, E. D. (2016) The natural evolutionary potential of tree populations to cope with newly introduced pests and pathogens-lessons learned from forest health catastrophes in recent decades. Current Forestry Reports, 2, 18-29.

Bull, J. J. (1994) Perspective: virulence. Evolution, 48, 1423-1437.

Bull, J. J. \& Ebert, D. (2008) Invasion thresholds and the evolution of nonequilibrium virulence. Evolutionary Applications, 1, 172-182.

Burdon, J. J., Thrall, P. H. \& Ericson, L. (2013) Genes, communities \& invasive species: understanding the ecological and evolutionary dynamics of host-pathogen interactions. Current Opinion in Plant Biology, 16(4), 400-405.

Busby, P. E., Ridout, M. \& Newcombe, G. (2016) Fungal endophytes: modifiers of plant disease. Plant Molecular Biology, 90, 645-655.

Chesson, P. (2000) Mechanisms of maintenance of species diversity. Annual Review of Ecology and Systematics, 31: 343366.

Chuine I., Atauri I.G.d.C., Kramer K. \& Hänninen H. (2013) Plant Development Models. In: Phenology: An Integrative Environmental Science (ed. Schwarz MD). Springer, Dordrecht, Netherlands, pp. 275-293.

Combes, C. (2001) Parasitism: the ecology and evolution of intimate interactions. University of Chicago Press.

Cronin, J. P., Rúa, M. A. \& Mitchell, C. E. (2014) Why is living fast dangerous? Disentangling the roles of resistance and tolerance of disease. The American Naturalist, 184, 172-187.

Cunniffe, N. J., Koskella, B., Metcalf, C. J. E., Parnell, S., Gottwald, T.R. \& Gilligan, C.A. (2015) Thirteen challenges in modelling plant diseases. Epidemics, 10, 6-10.

Dantec, C. F., Ducasse, H., Capdevielle, X., Fabreguettes, O., Delzon, S. \& Desprez-Loustau, M.L. (2015) Escape of spring frost and disease through phenological variations in oak populations along elevation gradients. Journal of Ecology, 103, 1044-1056.

Desprez-Loustau, M. L., Robin, C., Buee, M., Courtecuisse, R., Garbaye, J., Suffert, F., Sache, I. \& Rizzo, D.M. (2007) The fungal dimension of biological invasions. Trends in Ecology \& Evolution, 22, 472-480. 
Desprez-Loustau, M. L., Vitasse, Y., Delzon, S., Capdevielle, X., Marcais, B. \& Kremer, A. (2010) Are plant pathogen populations adapted for encounter with their host? A case study of phenological synchrony between oak and an obligate fungal parasite along an altitudinal gradient. Journal of Evolutionary Biology, 23, 87-97.

Desprez-Loustau, M. L., Feau, N., Mougou-Hamdane, A. \& Dutech, C. C. (2011) Interspecific and intraspecific diversity in oak powdery mildews in Europe: coevolution history and adaptation to their hosts. Mycoscience, 52, 165-173.

Desprez-Loustau, M. L., Saint-Jean, G., Barres, B., Dantec, C. \& Dutech, C. C. (2014) Oak powdery mildew changes growth patterns in its host tree: host tolerance response and potential manipulation of host physiology by the parasite. Annals of Forest Science, 71, 563-573.

Doumayrou, J., Avellan, A., Froissart, R. \& Michalakis, Y. (2013) An experimental test of the transmission-virulence tradeoff hypothesis in a plant virus. Evolution, 67, 477-486.

Ducousso, A., Guyon, J.P. \& Kremer, A. (1996) Latitudinal and altitudinal variation of bud burst in western populations of sessile oak (Quercus petraea (Matt) Liebl). Annals of Forest Science, 53, 775-782.

Edwards, M.C. \& Ayres, P.G. (1982) Seasonal changes in resistance of Quercus petraea (sessile oak) leaves to Microsphaera alphitoides. Transactions of the British Mycological Society, 78, 569-571.

Emmons, C. W. (1930) Cicinnobolus cesatii, a study in host-parasite relationships. Bulletin of the Torrey botanical Club, 57, 421-441.

Ennos, R. A. (2015) Resilience of forests to pathogens: an evolutionary ecology perspective. Forestry, 88, 41-52.

Escriu, F., Fraile, A. \& García-Arenal, F. (2003) The evolution of virulence in a plant virus. Evolution, 57, 755-765.

Feau, N., Decourcelle, T., Husson, C., Desprez Loustau, M. L. \& Dutech, C. C. (2011) Finding single copy genes out of sequenced genomes for multilocus phylogenetics in non-model fungi. Plos One, 6(4), e18803.

Feau, N., Lauron-Moreau, A., Piou, D., Marçais, B., Dutech, C. C. \& Desprez-Loustau, M. L. (2012) Niche partitioning of the genetic lineages of the oak powdery mildew complex. Fungal Ecology, 5, 154-162.

Fisher, M. C., Henk, D. A., Briggs, C. J., Brownstein, J. S., Madoff, L. C., McCraw, S. L. \& Gurr, S. J. (2012) Emerging fungal threats to animal, plant and ecosystem health. Nature, 484(7393), 186-194.

Fitt, B.D., Huang, Y., van den Bosch, F. \& West, J.S. (2006) Coexistence of related pathogen species on arable crops in space and time. Annual Review of Phytopathology, 44, 163-82.

Flory, S. L. \& Clay, K. (2013) Pathogen accumulation and long-term dynamics of plant invasions. Journal of Ecology, 101, 607-613.

Francl, L. J. (2001) The disease triangle: a plant pathological paradigm revisited. Plant Health Instructor, DOI: 10.1094/PHIT-2001-0517-01

Gilchrist, M. A., Sulsky, D. L., Pringle, A. (2006). Identifying fitness and optimal life-history strategies for an asexual filamentous fungus. Evolution, 60: 970-979.

Glawe, D. A. (2008) The powdery mildews: a review of the world's most familiar (yet poorly known) plant pathogens. Annual Review of Phytopathology, 46, 27-51.

Guillaume, F. \& Rougemont, J. (2006) Nemo: an evolutionary and population genetics programming framework. Bioinformatics, 22, 2556-2557.

Hajji, M., Dreyer, E. \& Marçais, B. (2009) Impact of Erysiphe alphitoides on transpiration and photosynthesis in Quercus robur leaves. European Journal of Plant Pathology, 125, 63-72.

Halkett, F., Harrington, R., Hullé, M., Kindlmann, P., Menu, F., Rispe, C. \& Plantegenest, M. (2004) Dynamics of production of sexual forms in aphids: theoretical and experimental evidence for adaptive "coin-flipping" plasticity. The American Naturalist, 163, E112-E125.

Hamelin, F. M., Castel, M., Poggi, S., Andrivon, D. \& Mailleret, L. (2011) Seasonality and the evolutionary divergence of plant parasites. Ecology, 92, 2159-2166.

Hamelin, F.M., Bisson A., Desprez-Loustau M.L., Fabre F. \& Mailleret L. (2016) Temporal niche differentiation of parasites sharing the same plant host: oak powdery mildew as a case study. Ecosphere, 7, e01517.

Huot, B., Yao, J., Montgomery, B. L. \& He, S. Y. (2014) Growth-defense tradeoffs in plants: a balancing act to optimize fitness. Molecular plant, 7, 1267-1287.

Jakuschkin, B., Fievet, V., Schwaller, L., Fort, T., Robin, C. \& Vacher, C. (2016) Deciphering the Pathobiome: Intra-and Interkingdom Interactions Involving the Pathogen Erysiphe alphitoides. Microbial Ecology, 72, 870-880.

Jarosz, A. M. \& Davelos, A. L. (1995) Effects of disease in wild plant populations and the evolution of pathogen aggressiveness. New Phytologist, 129, 371-387.

Jeger, M. J. (2000) Theory and plant epidemiology. Plant Pathology, 49, 651-658.

Jousimo, J., Tack, A. J., Ovaskainen, O., Mononen, T., Susi, H., Tollenaere, C. \& Laine, A. L. (2014) Ecological and evolutionary effects of fragmentation on infectious disease dynamics. Science, 344(6189), 1289-1293.

Keeling, M. J. \& Rohani, P. (2008) Modeling infectious diseases in humans and animals. Princeton University Press.

Kerling, L. C. P. (1966) The hibernation of the oak mildew. Plant Biology, 15, 76-83.

Kermack, W. O. \& McKendrick, A. G. (1927) A contribution to the mathematical theory of epidemics. Proceedings of the Royal Society of London A: Mathematical, Physical and Engineering sciences, 115, 700-721.

Kisdi, E. (2012) F1000 Prime Recommendation of [Hamelin FM et al., Ecology 2011, 92(12),2159-66]. F1000 Prime. 
Kiss, L., Russell, J. C., Szentiványi, O., Xu, X. \& Jeffries, P. (2004) Biology and biocontrol potential of Ampelomyces mycoparasites, natural antagonists of powdery mildew fungi. Biocontrol Science and Technology, 14, 635-651.

Lenski, R. E. \& May, R. M. (1994) The evolution of virulence in parasites and pathogens: reconciliation between two competing hypotheses. Journal of Theoretical Biology, 169, 253-265.

Limkaisang, S., Cunnington, J.H, Wui, L.K., Salleh, B., Sato, Y., Divarangkoon, R., Fangfuk, W., To-anun, C. \& Takamatsu, S. (2006) Molecular phylogenetic analyses reveal a close relationship between powdery mildew fungi on some tropical trees and Erysiphe alphitoides, an oak powdery mildew. Mycoscience, 47, 327-335.

Lively, C. M., de Roode, J. C., Duffy, M. A., Graham, A. L. \& Koskella, B. (2014) Interesting open questions in disease ecology and evolution. The American Naturalist, 184(S1), S1-S8.

Liyanage, A. D. S. \& Royle, D. J. (1976) Overwintering of Sphaerotheca humuli, the cause of hop powdery mildew. Annals of Applied Biology, 83, 381-394.

Loreau, M. (1992) Time scale of resource dynamics and coexistence through time partitioning. Theoretical Population Biology, 41, 401-412.

Loreau, M. \& Hector, A. (2001) Partitioning selection and complementarity in biodiversity experiments. Nature, 412(6842), 72-76.

Madden, L. V., Hughes, G. \& Bosch, F. (2007) The study of plant disease epidemics. American Phytopathological Society (APS Press).

Mailleret, L. \& Lemesle, V. (2009) A note on semi-discrete modelling in the life sciences. Philosophical Transactions of the Royal Society of London A: Mathematical, Physical and Engineering Sciences, 367, 4779-4799.

Mailleret, L., Castel, M., Montarry, J. \& Hamelin, F. M. (2012) From elaborate to compact seasonal plant epidemic models and back: is competitive exclusion in the details? Theoretical Ecology, 5, 311-324.

Marcais, B., Kavkova, M. \& Desprez-Loustau, M. L. (2009) Phenotypic variation in the phenology of ascospore production between European populations of oak powdery mildew. Annals of Forest Science, 66, 814.

Marcais, B. \& Desprez-Loustau, M. L. (2014) European oak powdery mildew: impact on trees, effects of environmental factors, and potential effects of climate change. Annals of Forest Science, 71, 633-642.

Marçais, B., Piou, D. , Dezette, D. \& Desprez-Loustau, M.L. (2017) Can oak powdery mildew severity be explained by indirect effects of climate on the composition of the Erysiphe pathogenic complex? Phytopathology, 107, 570-579.

Menzel, A. (2000). Trends in phenological phases in Europe between 1951 and 1996. International Journal of Biometeorology, 44(2), 76-81.

Montarry, J., Cartolaro, P., Delmotte, F., Jolivet, J. \& Willocquet, L. (2008) Genetic structure and aggressiveness of Erysiphe necator populations during grapevine powdery mildew epidemics. Applied and Environmental Microbiology, 74, 6327-6332.

Mordecai, E.A. (2011) Pathogen impacts on plant communities: unifying theory, concepts, and empirical work. Ecological Monographs, 81, 429-441.

Mougou, A., Dutech, C. C. \& Desprez-Loustau, M. L. (2008) New insights into the identity and origin of the causal agent of oak powdery mildew in Europe. Forest Pathology, 38, 275-287.

Mougou-Hamdane, A., Giresse, X., Dutech, C. C. \& Desprez Loustau, M. L. (2010) Spatial distribution of lineages of oak powdery mildew fungi in France, using quick molecular detection methods. Annals of Forest Science, 67, 212.

Newcombe, G. (1998) A review of exapted resistance to diseases of Populus. European Journal of Forest Pathology, 28, 209-216.

Pasco, C., Montarry, J., Marquer, B. \& Andrivon, D. (2016) And the nasty ones lose in the end: foliar pathogenicity trades off with asexual transmission in the Irish famine pathogen Phytophthora infestans. New Phytologist, 209, 334-342.

Pautasso, M., Holdenrieder, O. \& Stenlid, J. (2005) Susceptibility to fungal pathogens of forests differing in tree diversity. In: Forest diversity and function. Springer Berlin Heidelberg, pp. 263-289.

Pautasso, M., Aas, G., Queloz, V. \& Holdenrieder, O. (2013) European ash (Fraxinus excelsior) dieback-a conservation biology challenge. Biological Conservation, 158, 37-49.

Pearson, R. C. \& Gadoury, D. M. (1987) Cleistothecia, the source of primary inoculum for grape powdery mildew in New York. Phytopathology, 77, 1509-1514.

Penczykowski, R.M., Walker, E., Soubeyrand, S. \& Laine, A.L. (2015) Linking winter conditions to regional disease dynamics in a wild plant-pathogen metapopulation. New Phytologist, 205, 1142-1152.

Piepenbring, M., Hofmann, T. A., Kirschner, R., Mangelsdorff, R., Perdomo, O., Justavino, D.R. \& Trampe, T. (2011) Diversity patterns of Neotropical plant parasitic microfungi. Ecotropica, 17, 27-40.

Robinson, R. A. (1976) Plant pathosystems. Springer Berlin Heidelberg.

Plomion, C., Aury, J. M., Amselem, J. et al. (2016) Decoding the oak genome: public release of sequence data, assembly, annotation and publication strategies. Molecular ecology resources, 16, 254-265.

Roslin, T., Laine, A.-L. \& Gripenberg, S. (2007) Spatial population structure in an obligate plant pathogen colonizing oak Quercus robur. Functional Ecology, 21, 1168-1177.

Roy, B. A. \& Kirchner, J. W. (2000) Evolutionary dynamics of pathogen resistance and tolerance. Evolution, 54, 51-63.

Sacristan, S. \& Garcia-Arenal F. (2008). The evolution of virulence and pathogenicity in plant pathogen populations. Molecular Plant Pathology, 9, 369-384. 
Schoch, C. L., Seifert, K. A., Huhndorf, S., Robert, V., Spouge, J.L., Levesque, C.A. \& Chen, W. (2012) Nuclear ribosomal internal transcribed spacer (ITS) region as a universal DNA barcode marker for Fungi. Proceedings of the National Academy of Sciences, 109, 6241-6246.

Segarra, J., Jeger, M. J. \& Van den Bosch, F. (2001) Epidemic dynamics and patterns of plant diseases. Phytopathology, 91, 1001-1010.

Soularue, J. P. \& Kremer, A. (2012) Assortative mating and gene flow generate clinal phenological variation in trees. BMC evolutionary biology, 12, 79.

Sparks, T.H. \& Carey, P.D. (1995) The Responses of Species to Climate Over Two Centuries: An Analysis of the Marsham Phenological Record, 1736-1947. Journal of Ecology, 83, 321.

Sparks, T.H., Carey, P.D. \& Combes, J. (1997) First leafing dates of trees in Surrey between 1947 and 1996. The London Naturalist, 76, 15-20.

Spotts, R.A. \& Chen, P.M. (1984) Cold Hardiness and Temperature Responses of Healthy and Mildew-Infected Terminal Buds of Apple During Dormancy. Phytopathology, 74, 542-544.

Stukenbrock, E. H. \& McDonald, B. A. (2008) The origins of plant pathogens in agro-ecosystems. Annual Review of Phytopathology, 46, 75-100.

Susi, H., Barrès, B., Vale, P.F. \& Laine, A.L. (2015) Co-infection alters population dynamics of infectious disease. Nature Communications, 6, 5975.

Tack, A.J. \& Laine, A.L. (2014) Ecological and evolutionary implications of spatial heterogeneity during the off-season for a wild plant pathogen. New Phytologist, 202, 297-308.

Takamatsu, S., Braun, U., Limkaisang, S., Kom-un, S., Sato, Y. \& Cunnington, J.H. (2007) Phylogeny and taxonomy of the oak powdery mildew Erysiphe alphitoides sensu lato. Mycological research, 111, 809-826.

Takamatsu, S. (2013) Origin and evolution of the powdery mildews (Ascomycota, Erysiphales). Mycoscience, 54, 75-86.

Takamatsu, S., Ito, H., Shiroya, Y., Kiss, L. \& Heluta, V. (2015) First comprehensive phylogenetic analysis of the genus Erysiphe (Erysiphales, Erysiphaceae) I. The Microsphaera lineage. Mycologia, 107, 475-489.

Tedersoo, L., Bahram, M., Põlme, S., KolJalg, U., Yorou, N.S. et al. (2014) Global diversity and geography of soil fungi. Science, 346(6213), 1256688.

Tian, D., Traw, M. B., Chen, J. Q., Kreitman, M. \& Bergelson, J. (2003) Fitness costs of R-gene-mediated resistance in Arabidopsis thaliana. Nature, 423(6935), 74-77.

Tollenaere, C., Susi, H. \& Laine, A.-L. (2016) Evolutionary and Epidemiological Implications of Multiple Infection in Plants. Trends in Plant Science, 21, 80-90.

van den Berg, F., Bacaer, N., Metz, J. A. J., Lannou, C. \& van den Bosch, F. (2011) Periodic host absence can select for both higher or lower parasite transmission rates. Evolutionary Ecology, 25, 121-137.

Viennot-Bourgin, G. (1968) Note sur des Erysiphacees. Bulletin Trimestriel de la Societe Mycologique de France, 84, 117118.

Viney, R. (1970) L'oïdium du Chêne: incident léger ou désastre. Revue Forestière Française, 22, 365-369.

Vitasse, Y. (2013) Ontogenic changes rather than difference in temperature cause understory trees to leaf out earlier. New Phytologist, 198, 149-155.

Vitasse, Y., François, C., Delpierre, N. et al. (2011). Assessing the effects of climate change on the phenology of European temperate trees.Agricultural and Forest Meteorology, 151, 969-980

Vuillemin, P. (1910a) Le déclin de la maladie du blanc du chêne. Bulletin de l'Office forestier du Centre et de l'Ouest, 347350.

Vuillemin, P. (1910b) Un ennemi naturel de l'Oïdium du Chêne. Bulletin de la Société Mycologique de France, 26.

Weis, A. E., Simms, E. L. \& Hochberg, M. E. (2000) Will plant vigor and tolerance be genetically correlated? Effects of intrinsic growth rate and self-limitation on regrowth. Evolutionary Ecology, 14, 331-352.

Woodward, R. C. , Waldie, J. S. L. \& Steven, H. M. (1929) Oak mildew and its control in forest nurseries. Forestry, 3, 3856.

Zandt, P. A. V. \& Mopper, S. (1998) A meta-analysis of adaptive deme formation in phytophagous insect populations. The American Naturalist, 152, 595-604. 